\title{
The role of destination built environment on nonmotorized travel behavior: A case of Long Beach, California
}

\author{
Dohyung Kim, California State Polytechnic University - Pomona \\ Jiyoung Park, University at Buffalo, The State University of New York \\ Andy Hong, University of Southern California
}

\begin{abstract}
This study examines how built environment factors at trip destinations influence nonmotorized travel behavior in the City of Long Beach, California. A nested logit model consisting of 753 trips derived from the 2009 California Household Travel Survey (CHTS). The results indicate that density, diversity, and design at trip ends significantly affect travel decisions. Especially, transportation networks and nonmotorized facilities at trip destinations are important factors for nonmotorized mode choice. Future research should consider built environment factors at trip destinations to develop more effective nonmotorized transportation policies.
\end{abstract}

\section{Keywords}

Destination; built environment; nonmotorized transportation; mode choice; destination choice; nested logit model 


\section{Introduction}

Nonmotorized transportation, such as walking and biking, has recently garnered much attention among urban planners and decision makers. A growing body of research has found that nonmotorized travel has many social, environmental, and health benefits (Pucher and Buehler 2010; de Nazelle et al. 2011; Woodcock et al. 2007). However, it remains a marginal mode of travel in the U.S., accounting for about 10\% of all trips (Pucher and Buehler 2010). To promote nonmotorized travel, planners and decision-makers have tried various strategies, such as 'New Urbanism' and 'Smart Growth' policies, which aim at changing urban form to accommodate more walking and bicycling (Duany et al. 2001; Calthorpe 1993; Knaap and Talen 2005). One of the key aspects of the policies is the potential role of the built environment in influencing individual travel decisions and that compact and mixed-use development can encourage more walking, bicycling, and transit use.

In theorizing the effects of built environment on travel behavior, Cervero and Kockelman (1997) operationalized built environment features into measurable elements and popularized the term 4-Ds: density, diversity, design, and destination accessibility. An extensive volume of urban planning literature has followed to establish the causal relationship between the built environment and travel behavior, for example, National Academy of Sciences (2009) provides a comprehensive discussion on this topic. In contrast, transportation researchers have rarely examined the full range of the built environment factors in developing travel demand models, leaving much of the urban planning literature silent. In a traditional four-step travel demand model, modelers often consider land use as synonymous with zonal population and employment distributions (Ortuzar and Willumsen 2011). This traditional model includes simple built environment variables, such as population density and job accessibility, to estimate general patterns of aggregate travel behavior. Activity-based models, which are considered to be a significant improvement over the traditional models, put even less emphasis on the built environment but focus more on a substance of activities performed at trip destinations (Axhausen and Gärling 1992).

In this paper, we attempt to reconcile this gap between urban planning and transportation research by incorporating comprehensive built environment factors at trip destinations for investigating nonmotorized travel behavior. We hypothesize that built environment features at trip destinations can influence destination choice and mode choice decisions. We also hypothesize that the effects of the built environment on travel behavior differ between nonmotorists and motorists. Following these hypotheses, a nested logit model was developed to investigate the effects of the built environment on trip destination and mode choice in Long Beach, California. The nested logit model allowed for examining systematic differences in travel behavior between nonmotorists and motorists. The results illuminate the important aspects of spatial heterogeneity in destination and mode choice behavior. This study provides new insight into future policy and research, suggesting that the built environment at trip destinations can be an important factor for promoting nonmotorized travel. 


\section{Literature Review}

\section{Built environment and nonmotorized travel behavior}

Over the past several decades in urban planning research, the 'New Urbanism' and 'Smart Growth' rhetoric has spurred many studies investigating the relationship between land use and travel behavior. In theorizing the effects of land use on travel behavior, Cervero and Kockelman (1997) operationalized built environment features into measurable elements and popularized the term 4-Ds: density, diversity, design, and destination accessibility. According to the 4-D approach, residential density, land use mix, and street network patterns are considered to be important factors that affect individual travel behavior.

Under this theoretical framework, Ewing and Cervero (2010) conducted a meta-analysis and calculated average elasticity for travel variables in an attempt to provide overall elasticity for the four dimensions of the built environment. Their research indicated that vehicle miles traveled (VMT) is highly associated with an accessibility measure, whereas walking and transit trips are more related with design and diversity dimension. In a subsequent study, Ewing et. al (2014) used empirical data pooled from 15 US regions to confirm the results of the above meta-analysis. They found a strong influence of design, diversity, and destination accessibility on travel behavior, and the land use effects for different travel modes varied by spatial scale. This result is not surprising given that different modes operate at different geographic scales.

Handy (1993) and Boarnet and Greenwald (2000) found that a regional accessibility and a local accessibility influences walking and driving behavior differently for non-work travel. For that matter, the impact of accessibility, which includes connections between origin and destination, on modal behavior may vary depending on different geographic scales.

Most travel behavior literature focuses on automobile, but the findings from these studies offer valuable insight into understanding nonmotorized travel (Badoe and Miller 2000; Bartholomew and Ewing 2008; Bento et al. 2005; Brownstone and Golob 2009). They generally found significant relationships between auto use and macro-level built environment features, such as density and accessibility. Other researchers have examined the impact of the neighborhood urban form using more sophisticated models incorporating travel costs (i.e. trip lengths and trip distances) and found mixed results with regard to the effects of the built environment on travel (Crane and Crepeau 1998; Greenwald and Boarnet 2001). Recent attention has been given to studying the confounding effect of residential self-selection, which is the tendency of individuals to sort themselves into certain neighborhoods based on their travel preferences (Handy et al. 2006; Mokhtarian 2008; Cao et al. 2009). A general consensus among the researchers is that while residential self-selection is an important factor, the built environment still matters. Other researchers have explored the role of attitudes and preferences and found significant effects of the attitudinal measures on travel behavior, suggesting that "soft" measures, such as educational campaigns and programs, can be complementary to conventional land use-based policies (Joh et al. 2011; Van Acker et al. 2010).

Parallel to this growing interest in attitudes and self-selection in urban planning research, another useful theoretical development on understanding nonmotorized travel behavior emerged 
from psychology and public health. Among the most prominent theory in the context of built environment and nonmotorized travel behavior is the ecological model (Saelens et al. 2003; Sallis 2009). This model focuses on the interplay between individual, social, and physical environmental factors to understand individual behavior, thus aiming to encourage active travel through a multi-faceted strategy (Giles-Corti and Donovan 2002). Although this model was developed by psychologists and public health researchers, it has gained wide support from urban planning and transportation community because it enables integration of existing land use and transportation policies into promotion of active travel, contributing towards creating more sustainable and healthier lifestyles (Sallis et al. 2006; Handy et al. 2002). Advancement in theoretical understanding of nonmotorized travel behavior has been fueled by this interdisciplinary research effort, often referred to as active living research which focuses on synergies between the built environment and nonomotorized travel (Bussel et al. 2009).

\section{Advance in travel demand modelling}

In contrast to urban planning researchers' profound interests in built environment, transportation researchers have rarely considered the full range of the built environment for explaining travel behavior. Traditional four-step models include some land use variables for analyzing trip generation and mode choice (Ortuzar and Willumsen 2011). However, these land use variables are aggregated at the zonal or regional level, leaving out many of the detailed and nuanced land use characteristics. Moreover, few transportation modeling studies have examined the systematic impacts of the built environment on destination and mode choice decisions at the disaggregate level. Most of the discussion on transportation modeling tends to focus on the temporal ordering of traveler's decision on mode choice and destination (Newman and Bernardin 2010) or the model efficiency between sequential procedure and combined model formulation of mode choice and destination (Boyce 2002; Siegel et al. 2006). Several attempts have been made to include more comprehensive built environment factors for modeling mode choice. However, their purpose was to understand the joint impact of long-term residential location and mode choice on travel behavior, rather than understanding the influence of destination characteristics on travel behavior (Bhat and Guo 2007; Pinjari et al. 2007).

Activity-based approach, which is considered the next-generation travel demand model, pays even less attention on land use factors. Activity-based models focus on individual's activity participation through joint modeling of individual destination and mode choice decisions linked with various types of activities at destinations (Ben-Akiva and Bierlaire 1999). Unlike the traditional four-step models where nonmotorized trips are hardly included in modeling procedures, activity-based models have the capability to incorporate nonomotorized travel. However, few operational activity-based models to date include a full range of built environment factors into modeling travel behavior because of substantial data and computational requirements associated with model development (Liu et al. 2012). Some of the recent activity-based research considers built environment factors, but most of them use simple measures, such as employment and population density, and distance to central business district (Bowman and Ben-Akiva 2000; 
Pinjari et al. 2011). The activity-based approach is a more promising solution than the conventional four-step models, but it still lacks adequate consideration of built environment factors at trip destinations.

\section{Research gaps and objectives}

As evident in the current direction of the travel demand modeling, land use-travel behavior research is moving toward a more integrated and disaggregated approach focusing on individual's decisions and activities at trip destination. In urban planning literature, however, surprisingly little attention has been paid to the role of destination on travel behavior. According to a classic economic theory, travel is a derived demand from the need to participate in activities distributed in space (Small and Verhoef 2007). Because the activities performed at trip destinations largely determine the basic travel demand structure, trip destination serves as a critical factor for explaining travel behavior (Boarnet and Crane 2001). The recent activity-based travel behavior models are an extension of this economic theory, by assuming that the demand for certain activity at a trip destination influences individual travel decisions (Domencich and McFadden 1975).

However, most urban planning and transportation literature either focuses on the influence of the built environment at trip origin or uses a crude measure of destination factors. As noted by Handy $(2002,230)$, limiting the discussion to trip origin is an artificial restriction because most activities occur outside the home. For nonmotorized travelers, built environment characteristics at trip destinations can be as important as utilities or functional needs at trip destinations (Forsyth and Krizek 2011; Zhang 2004). However, with some notable exceptions (Frank and Pivo 1994; Shafizadeh and Niemeier 1997; Iacono et al. 2010), much of the discussion on land use-travel behavior research is focused on residential land use rather than the built environment context at trip ends (Boarnet et al. 2008; Cervero and Duncan 2003; Chatman 2009).

To overcome this limitation, we empirically examine the role of destination on travel behavior by modeling destination and mode choice decisions for nonmotorized travelers. We hypothesize that built environment characteristics at trip destinations affect travel decisions and develop a nested logit model to understand the complex mechanism behind individual destination and mode choice decisions for nonmotorists. As many cities are experimenting with a variety of land use policies to promote nonmotorized travel, it is important to understand not only built environment features at trip origin but also at trip end, and how different mode users might respond to different elements of the built environment at trip ends. This study seeks to understand the role of destination on travel behavior of nonmotorized travelers and to inform planners and policy-makers in facilitating the development of effective nonmotorized transportation policy. 


\section{Methods}

\section{Study area and data sources}

The study area is the City of Long Beach located about 22 miles south of downtown Los Angeles. Long Beach encompasses 52 square-miles, which includes both suburban and urban settings. As of 2009, it is the 36th largest city in the nation and the sixth largest in California. According to Census 2010, Long Beach has experienced a slow population growth $(0.5 \%)$ during the last five years, compared to LA County (3.1\%) and the state of California (10\%). In terms of the transportation environment, Long Beach has a supportive environment for nonmotorized transportation. Its climate and flat terrain make it ideal for walking and bicycling. Long Beach adopted a bicycle master plan in 2001 and has implemented approximately 63 miles of bikeways (Alta Transportation Consulting 2001). The city is also aggressively moving forward with a plan to implement a new bike sharing program, which allows convenient access to bicycles for visitors and non-bicyclists (City of Long Beach 2013).

The primary data source is the 2009 California Household Travel Survey (CHTS). It is a nationally representative one-day sample of household and individual travel behavior, containing travel survey data geocoded at the individual level. We used the CHTS sample corresponding to the City of Long Beach, the total 809 destinations for all modes within the city. To supplement the CHTS data, we obtained parcel-based land use data obtained from Southern California Association of Governments (SCAG), and the InfoUSA database which provides business information linked to the land use data through the six-digit NAICS code. Information regarding transit stops and bicycle facilities were obtained from Metropolitan Transit Authority (MTA). We used ArcGIS software (ESRI, Redlands CA, version 10) to quantify the built environment characteristics around trip destinations and conducted statistical analyses using NLOGIT software (Econometric Software, NY).

\section{Research Methodology}

\section{Nested logit model (NLM)}

The research methodology employed was a nested logit model to capture two different but related behavioral components: destination choice and mode choice decisions. A mode choice decision is a classic example of multinomial logit (MNL) application. The MNL model for the mode choice assumes "the ratio of the choice probability of any two alternatives is independent and irrelevant," so-called Independence and Irrelevance Alternatives (IIA) assumption (Liao 1994). However, mode choice decision and destination decision are correlated with one another in this study, violating this IIA assumption. Therefore, we developed two structures to overcome this correlation problem.

As illustrated in 
Figure 1, our decision tree first hypothesizes a trip destination, and then, selects a travel mode. The upper level consists of what we call a destination choice model, which measures the influence of the built environment on the destination choice. The model hypothesizes that nonmotorists prefer certain built environment features at trip destinations; in consequence, it generates a clear spatial distinction between nonmotorists and motorists. Thus, we developed a destination choice model to determine which built environment features of destinations in "clustered group" are related in contrast to ones in "non-clustered group".

The lower level of the model is called the mode choice model, which focuses on the influence of the remaining built environment variables and socio-economic characteristics on individual mode choice decision. To explain the rationale behind the mode choice model, people who travel to the clustered destinations by bicycle or on foot could also drive their cars to the non-clustered destinations. This model is capable of explaining why some people decide to walk or bike while some others decide to drive. Thus, the mode choice model hypothesizes that built environment characteristics of destinations significantly affect different mode choice behaviors, after controlling for individual socioeconomic characteristics. Note determinants for destination choice and mode choice behaviors are not identical, and hence, two sets of independent variables that best represent each behavior were selected.

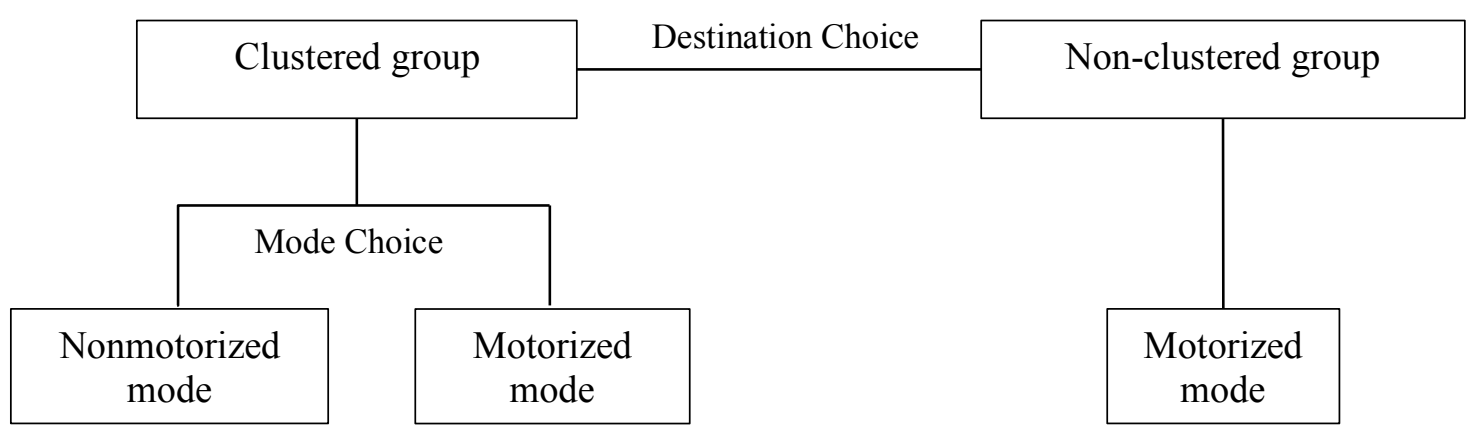

\section{Figure 1. Decision tree for destination and mode choice}

We developed a simple unconditional MNL model based on the nonmotorized trips to the clustered destinations (reference group), automobile trips to the clustered destinations, and automobile trips to non-clustered destinations. This MNL regression provides the initial coefficients for the later NLM runs that are optimized with full information maximum likelihood (FIML) method. Therefore, firstly, the details of the MNL model are explained in equations (1) through (4). Applying the MNL model requires calculating behavioral decision making proportional to the sum of three trip behaviors. That is,

$$
\begin{aligned}
& \operatorname{Prob}(y=C N M T)=\frac{e^{U_{C N M T}}}{e^{U_{C M T}}+e^{U_{C N M T}}+e^{U_{N C M T}}}, \\
& \operatorname{Prob}(y=N C M T)=\frac{e^{U_{N C M T}}}{e^{U_{C M T}}+e^{U_{C M M T}}+e^{U_{N C M T}}},
\end{aligned}
$$


$\operatorname{Prob}(y=C M T)=\frac{e^{U_{C M T}}}{e^{U_{C M T}}+e^{U_{C M M T}}+e^{U_{N C M T}}}$, and

where $U_{j}$ is utility function of $j$ mode;

$j=$ Clustered motorized trip (CMT) or non-cluster motorized trip (NCMT); and $\mathrm{CNMT}=$ clustered non-motorized trip

Also, $\log \left[\frac{\operatorname{Prob}(\mathrm{y}=j)}{\operatorname{Prob}(\mathrm{y}=C N M T)}\right]=\sum_{i} \beta_{i}^{j} X_{i}$,

where $j=$ Clustered motorized trip (CMT) or non-cluster motorized trip (NCMT); and $i=$ independent variables, $X$, affecting the behavior choice including $4 \mathrm{D}$ variables.

Equation (2) connects log transformed odds ratio for a choice of behavior $j$ in the left hand side to the product of the parameters and independent variables as a linear structure. Hence, by introducing a multinomial logit link function defined as,

$$
\begin{aligned}
g^{j}(x) & =\sum_{i} \beta_{i}^{j} X_{i} \\
& =\log \left[\frac{\operatorname{Prob}(y=j)}{\operatorname{Prob}(y=\mathrm{CMT})}\right]
\end{aligned}
$$

We can substitute the utility function of $U_{j}$ with multinomial logit link function $g^{j}(\mathrm{x})$ and combine the equations (1) and (2). The utility function of the behavior choice is estimated in equation (4).

$U_{j}(x)=\sum_{i} \beta_{i}^{j} X_{i}$

The predicted $U_{j}(\mathrm{x})$ is added to calculate the probability of behavior choice in equations (1). Because the IIA assumption may not be supported in the behavior choices as shown in Figure 2, we introduce a nested logit model which provides inclusive value variables. If the clustered destinations affect individual travel behaviors differently, the inclusive value of the clustered branch would be significant. The NLM approach is described in equations (5) and (6).

$$
\begin{aligned}
& \operatorname{Prob}(y=C N M T \mid C)=\frac{e^{U_{C M M T} \mid C}}{e^{U_{C M I} \mid C}+e^{U_{C M M I} T}}, \\
& \operatorname{Prob}(y=C M T \mid C)=\frac{e^{U_{C M I} \mid C}}{e^{U_{C M T} \mid C}+e^{U_{C M M T} \mid C}}, \text { and }
\end{aligned}
$$


$\operatorname{Prob}(y=N C M T \mid N C)=\frac{e^{U_{\text {NСмT }} \mid N C}}{e^{U_{\text {NСMT }} \mid N C}}=1$,

where $C=$ Clustered destinations and $N C=$ Non-clustered destinations.

$\operatorname{Prob}(y=C)=\frac{e^{U_{C}+\tau_{C} I_{C}}}{e^{U_{C}+\tau_{C} I_{C}}+e^{U_{N C}+\tau_{N C} I_{N C}}}=\frac{e^{U_{C}+\tau_{C} I_{C}}}{e^{U_{C}+\tau_{C} I_{C}}+e^{U_{N C}+I_{N C}}}$, and

$\operatorname{Prob}(y=N C)=\frac{e^{U_{N C}+I_{N C}}}{e^{U_{C}+\tau_{C} I_{C}}+e^{U_{N C}+I_{N C}}}$.

where $\tau_{C}=$ parameters of $I_{C}$;

$\tau_{N C}=$ parameters of $I_{N C}$ and is restricted to 1.

$I_{C}=$ Inclusive value for clustered $(C)$ branch, defined as $\log \left(e^{U_{C M T}}+e^{U_{C M M T}}\right)$; and

$I_{N C}=$ Inclusive value for non-clustered $(N C)$ branch, defined as $\log \left(e^{U_{N C M T}}\right)$.

However, because equations (5) and (6) only count observations under each branch, to fully include all observations in equations (5) and (6), inclusive values were re-estimated with MLM based on the initial estimates. This is full information maximum likelihood (FIML) approach (Greene, 2000). Therefore, for example, the conditional probability of the clustered motorized trip (CMT) is calculated as,

$\operatorname{Prob}(y=C M T, C)=\operatorname{Prob}(y=C M T \mid C) \times \operatorname{Prob}(y=C)$.

\section{Spatial classification}

For the destination choice model, the first step was to conduct a spatial classification of 809 trip destinations by all travel modes. We excluded 31 destinations accessed by public transit in order to focus on the comparison between nonmotorized and motorized modes. In addition, two records that contained negative travel time numbers were excluded since they are considered as data entry error. After geocoding 776 trip destinations accessed by either motorized or nonmotorized modes, a dummy variable was created to indicate whether a destination was traveled by a motorized mode or a nonmotorized mode.

We then calculated Moran's I statistics to determine the degrees of spatial autocorrelation of destinations accessed by a nonmotorized mode. The spatial autocorrelation analysis allowed for simultaneously evaluating whether the given spatial pattern was clustered, dispersed, or random (Mitchell 2005). Of the 776 destinations, 130 destinations were accessed by nonmotorized modes. Of the 130 destinations, 105 trip destinations show spatial clustering patterns by nonmotorized trips at the $95 \%$ confidence level $(\mathrm{p}<0.05)$, while 25 destinations indicate non-spatial clustering. We excluded the 25 destinations, since they are geographically separated from the spatial clusters of nonmotorized trips.

A quarter-mile circular buffer was created for all the 105 nonmotorized trip destinations , and they were labeled as a clustered group (Error! Reference source not found.). Motorized trip destinations showed no particular clustering patterns, and thus they were included in the 
analysis as a comparison group. 411 motorized trip destinations which do not fall within the quarter-mile buffer were labeled as a non-cluster group and were included in the destination choice model. The rest of the 235 motorized trip destinations which fall within the quarter-mile buffer were included in the mode choice model for the clustered group. Therefore, the final model contains a total of 751 trip destinations.

The quarter-mile buffer represents the smallest catchment area for nomotorized mode. Since this paper focuses on the characteristics of trip destination, we took the most conservative approach by employing the smallest spatial scale. A typical catchment area for pedestrians and bicyclists is half mile and three miles, respectively (Plaut 2005; Iacono et al. 2008). However, these boundaries do not adequately serve for this study because they represent the distance between trip origin and destination. Furthermore, a large buffer caused an overlapping between multiple catchment areas because of spatially clustered destinations in our study area. We were concerned that a buffer size larger than a quarter-mile would lead to possible instances of double counting of built environmental factors. Therefore, we carefully chose the quarter-mile buffer to be more conservative and to avoid potential overestimation of land use effects.

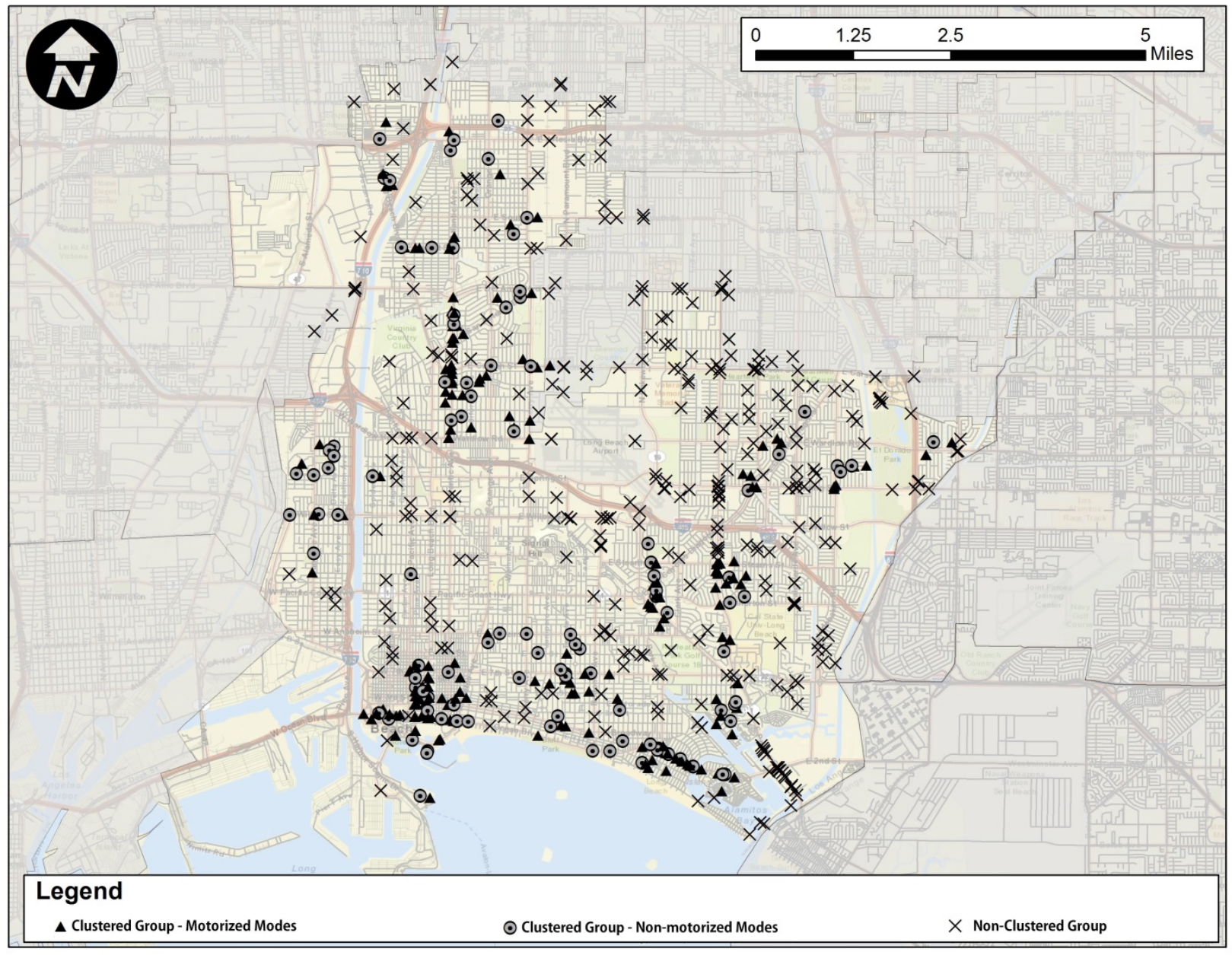

Figure 2. Trip destinations by travel modes

\section{Description of data}


Dependent variables. The dependent variable for the destination choice model is simply a binary variable indicating whether or not a nonmotorized trip destination is in the clustered group. We obtained this binary measure from a spatial autocorrelation analysis which examined each destination based on the probability of spatial clustering of nonmotorized trips at the $95 \%$ confidence level. The mode choice model uses a categorical measure identified as one of the three types of destinations: 1) nonmotorized destinations in the clustered group; 2) motorized destinations in the clustered group; and 3) motorized destinations in the non-clustered group. In the mode choice model, the nonmotorized destinations in the clustered group were used as a reference group.

Independent variables. A broad range of built environment elements were quantified within a quarter-mile circular buffer of each trip destination. Each built environment feature within this quarter-mile boundary was aggregated and associated with each trip destination. For example, we computed the number of residents and jobs within the surrounding buffer, and obtained the density variable by normalizing the number by 125.66 , which is the total acreage of the quarter-mile boundary.

Table 1 illustrates all independent variables and their descriptions. We applied the classic 4-D approach proposed by Cervero and Kockelman (1997) to quantify the built environment features. The built environment features favorable to nonmotorized travel include compact/higher density development, a diverse and complementary mix of uses, consistent street grid and design features, and high levels of accessibility via mass transit (Cervero et al. 2009). Thus, the 4-D variables were used in both the mode choice and destination choice models. Some built environment measures capture similar effects of land use, possibly resulting in inflated standard errors and confidence intervals. Thus, we used the variance inflation factor (VIF) to determine the degree of multicollinearity across the built environment variables. Throughout this process, the 4-D variables with high VIF values such as employment density, mix of jobs, average floor area ratio (FRA), and retail destination were excluded.

\section{Table 1. Description of variables}

\begin{tabular}{l|l|l|l}
\hline Categories & Variables & Descriptions & Unit \\
\hline $\begin{array}{l}\text { Density } \\
\text { Variable }\end{array}$ & ACT_DEN & $\begin{array}{l}\text { Net population and employment density (sum of population } \\
\text { and employment divided by acreages of all parcels except } \\
\text { vacant, recreational, utilities agricultural, and } \\
\text { transportation) }\end{array}$ & people/acre \\
\hline $\begin{array}{l}\text { Diversity } \\
\text { Variables }\end{array}$ & LU_MIX & $\begin{array}{l}\text { Mix of five land use types (single family residential, } \\
\text { multifamily residential, commercial, industrial, and public) } \\
\text { Land use dissimilarity index } \\
\text { Land use balance index that is normalized with respect to } \\
\text { the natural log of the number of distinct uses considered } \\
\text { Single family and multifamily housing mix }\end{array}$ & ratio \\
\hline
\end{tabular}




\begin{tabular}{|c|c|c|c|}
\hline $\begin{array}{l}\text { Design } \\
\text { Variables }\end{array}$ & $\begin{array}{l}4 \mathrm{~W} \_ \text {INT } \\
\text { W_INX } \\
\text { ST_DEN } \\
\text { BIKE }\end{array}$ & $\begin{array}{l}\text { The percent of } 4 \text {-way intersections } \\
\text { Weighted intersection density by } 4 \text { way ( } 1 \text { ) and } 3 \text { way }(0.5) \\
\text { intersection } \\
\text { Street centerline density } \\
\text { Length of bicycle facilities in feet }\end{array}$ & $\begin{array}{l}\text { percent } \\
\text { density } \\
\text { density } \\
\text { feet } / 1000\end{array}$ \\
\hline $\begin{array}{l}\text { Destination } \\
\text { Variables }\end{array}$ & $\begin{array}{l}\text { FOOD } \\
\text { T_STOPS } \\
\text { SCHLS }\end{array}$ & $\begin{array}{l}\text { Number of food or restaurant business } \\
\text { Number of bus stops and rail transit stations } \\
\text { Number of schools }\end{array}$ & $\begin{array}{l}\text { numeric } \\
\text { numeric } \\
\text { numeric }\end{array}$ \\
\hline $\begin{array}{l}\text { Socio- } \\
\text { demographic } \\
\text { Variables }\end{array}$ & $\begin{array}{l}\text { LOW_INC } \\
\text { MED_INC } \\
\text { HH_SIZE } \\
\text { EDUC31 } \\
\text { HIS_R } \\
\text { AS_R } \\
\text { AA_R } \\
\text { GENDER }\end{array}$ & $\begin{array}{l}\text { Household income less than } \$ 35,000, \text { Yes }=1, \text { No }=0 \\
\text { Household Income between } \$ 35,000 \text { and } \$ 75,000, \text { Yes }=1 \text {, } \\
\text { No }=0 \\
\text { Count of household members } \\
\text { Bachelor degree and above, Yes }=1, \mathrm{No}=0 \\
\text { Hispanic household. Yes }=1, \mathrm{No}=0 \\
\text { Asian household, Yes }=1, \mathrm{No}=0 \\
\text { African American household, Yes }=1, \mathrm{No}=0 \\
\text { Male }=0, \text { Female }=1\end{array}$ & $\begin{array}{l}\text { dummy } \\
\text { dummy } \\
\text { number } \\
\text { dummy } \\
\text { dummy } \\
\text { dummy } \\
\text { dummy } \\
\text { dummy }\end{array}$ \\
\hline $\begin{array}{l}\text { Time } \\
\text { Variable }\end{array}$ & TRIP_T & Travel time in minute & minutes \\
\hline
\end{tabular}

The density variable, ACT_DEN, refers to the population and employment density around trip origin and destination. Following the method from previous studies (Ewing et al. 2015), we computed an overall activity density per areal unit by combining population and employment density. This variable measures trip-chains which include home as a trip destination as well as other non-home based travel destinations (Kuzmyak et al. 2012).

The diversity variables measure the diversity of land use and housing types. The land use mix variable, LU_MIX, represents the balance of five land use types based on the following formula.

$$
L U_{-} M I X=\frac{-(S F \times L N(S F)+M F \times L N(M F)+C O M \times L N(C O M)+I N D \times L N(I N D)+P U B \times L N(P U B))}{L N(5)}
$$

Where SF = percent of single family land use

$\mathrm{MF}=$ percent of multifamily land use

$\mathrm{COM}=$ percent of commercial land use

$\mathrm{IND}=$ percent of industrial land use

PUB $=$ percent of public land use

$\mathrm{LN}=$ the natural logarithm of a number 
The land use diversity variable, LU_DIS, refers to dissimilarity index, the proportion of dissimilar land uses among a parcel and surrounding parcels within an area. The following formula was used.

$$
L U \_D I S=\sum_{j}^{k} \sum_{I}^{8} \frac{\left(\frac{X_{I}}{8}\right)}{K}
$$

Where $\mathrm{K}=$ number of actively developed parcel in the buffer, and $\mathrm{X}_{\mathrm{I}}=1$ if land-use of neighboring parcel differs from parcel, $\mathrm{j}$ ( 0 otherwise).

The land use balance variable, LU_ENT, refers to land use entropy, which reflects the uniformity of land use mixtures. The following formula was used.

$$
L U_{-} E N T=\sum \frac{P_{j} \times \ln \left(p_{j}\right)}{\ln (\mathrm{J})}
$$

Where: $\mathrm{p}_{\mathrm{j}}=$ proportion of land-use category $\mathrm{j}$ within the buffer, and $\mathrm{J}=$ number of land-use categories

Similar to the land use mix variable, the housing mix variable, H_MIX, captures the balance between single family and multifamily dwelling units using the following formula.

$$
H_{-} M I X=\frac{-(S F \times L N(S F)+M F \times L N(M F))}{L N(2)}
$$

Where SF $=$ percent of single family housing units

$\mathrm{MF}=$ percent of multifamily housing units

$\mathrm{LN}=$ the natural logarithm of a number

The design variables include four variables, mostly representing roadway characteristics under study. This BIKE variable represents a total length of bicycle facilities in feet within the quarter-mile boundary, divided by 1,000 to adjust the decimal points for the estimated coefficients. For the mode choice model, we also included control variables, including sociodemographics and travel time, because of their potential influence on mode choice decision. The time variable, TRIP_T, represents the travel time from trip origin to destination, and it was obtained from the travel survey. One presumably important variable is sidewalk length and density, but the sidewalk variable was not included in this study. Most of the street segments within the study area have well-established sidewalks; therefore, the inclusion of sidewalk data would have minimal impact on the model results. 


\section{Results}

\section{Descriptive statistics}

The socio-demographic characteristics of the samples are comparable to ones of the citywide population. Compared to the citywide poverty level of $19.4 \%, 22 \%$ of the study sample had a household income less than $\$ 35,000$. About $31 \%$ of the sample's household income ranges between $\$ 35,000$ and $\$ 75,000$, while the city's median household income is $\$ 52,845$ by the 2010 Census. The household size is also identical; 2.8 for the city and 2.75 for the sample.

Error! Not a valid bookmark self-reference. presents the independent variables and their descriptive statistics. In the destination choice model, the clustered group has higher mean values for all the built environment measures than the non-clustered group. This suggests that the clustered group is more suitable for nonmotorized travel. Compared to the non-clustered group, walkability index (W_INX) is considerably higher in the clustered group. Also, the clustered group have much more food and restaurant establishments (FOOD) and transit stops (TSTOPS) than the non-clustered group.

Table 2. The descriptive statistics of the variables used for nested logit models

\begin{tabular}{|c|c|c|c|c|c|c|c|c|c|}
\hline \multicolumn{10}{|c|}{ Destination Choice Model } \\
\hline \multirow{2}{*}{ Categories } & \multirow{2}{*}{ Variable } & \multicolumn{4}{|c|}{ Clustered Areas } & \multicolumn{4}{|c|}{ Non-clustered Areas } \\
\hline & & Mean & Std.Dev. & Min. & Max. & Mean & Std.Dev. & Min. & Max. \\
\hline \multirow{2}{*}{ Design } & ST_DEN & 5.64 & 1.59 & 1.53 & 10.61 & 4.21 & 1.63 & 0.67 & 8.73 \\
\hline & W_INX & 37.72 & 20.53 & 4.30 & 97.3 & 20.75 & 12.98 & 0.60 & 78.90 \\
\hline \multirow{3}{*}{ Destination } & FOOD & 31.24 & 29.62 & 0.00 & 137.00 & 15.59 & 14.86 & 0.00 & 94.00 \\
\hline & TSTOPS & 63.14 & 85.55 & 0.00 & 413.00 & 20.80 & 24.62 & 0.00 & 256.00 \\
\hline & SCHLS & 0.41 & 0.74 & 0.00 & 4.00 & 0.22 & 0.49 & 0.00 & 3.00 \\
\hline Travel time & TRIP_T & 19.93 & 19.65 & 1.00 & 135.00 & 20.20 & 26.52 & 1.00 & 360.00 \\
\hline \multicolumn{10}{|c|}{ Mode Choice Model } \\
\hline \multirow{2}{*}{ Categories } & \multirow{2}{*}{ Variable } & \multicolumn{4}{|c|}{ Nonmotorized Trips } & \multicolumn{4}{|c|}{ Motorized Trips } \\
\hline & & Mean & Std.Dev. & Min. & Max. & Mean & Std.Dev. & Min. & Max. \\
\hline Density & ACT_DEN & 56.78 & 45.97 & 0.00 & 231.57 & 51.80 & 34.08 & 0.00 & 221.40 \\
\hline \multirow{4}{*}{ Diversity } & LU_MIX & 0.47 & 2.11 & 0.00 & 0.89 & 0.46 & 0.22 & 0.00 & 0.82 \\
\hline & LU_DIS & 15.90 & 2.91 & 12.50 & 26.95 & 16.57 & 3.51 & 12.50 & 26.95 \\
\hline & LU_ENT & 0.54 & 0.11 & 0.08 & 0.78 & 0.54 & 0.11 & 0.08 & 0.72 \\
\hline & H_MIX & 0.41 & 0.40 & 0.00 & 1.00 & 0.44 & 0.37 & 0.00 & 1.00 \\
\hline \multirow{2}{*}{ Design } & $4 \mathrm{~W} \_I N T$ & 46.27 & 13.49 & 8.30 & 94.10 & 44.66 & 14.70 & 2.90 & 82.10 \\
\hline & BIKE & 2.35 & 1.87 & 0.00 & 8.22 & 2.01 & 2.12 & 0.00 & 7.73 \\
\hline Travel time & TRIP_T & 15.52 & 14.14 & 1.00 & 110.00 & 21.90 & 21.38 & 1.00 & 135.00 \\
\hline \multirow{8}{*}{$\begin{array}{c}\text { Socio- } \\
\text { demographic }\end{array}$} & LOW_INC & 0.19 & 0.39 & - & - & 0.20 & 0.40 & - & - \\
\hline & MED_INC & 0.47 & 0.50 & - & - & 0.29 & 0.46 & - & - \\
\hline & HH_SIZE & 2.89 & 1.60 & 1.00 & 6.00 & 2.78 & 1.41 & 1.00 & 1.70 \\
\hline & EDUC31 & 0.53 & 0.53 & - & - & 0.50 & 0.50 & - & - \\
\hline & HIS_R & 0.13 & 0.34 & - & - & 0.09 & 0.28 & - & - \\
\hline & AS_R & 0.06 & 0.23 & - & - & 0.06 & 0.24 & - & - \\
\hline & AA_R & 0.04 & 0.19 & - & - & 0.13 & 0.33 & - & - \\
\hline & GENDER & 0.56 & 0.50 & - & - & 0.58 & 0.49 & - & - \\
\hline
\end{tabular}


In the mode choice model, the built environment characteristics vary by travel modes, although the differences are not as pronounced as in the destination choice model. Built environment features are expected to be similar because the destinations in the clustered group are spatially close to each other. However, activity density (ACT_DEN), proportion of 4-way intersection (4W_INT), and the number of bicycle facilities (BIKE) are slightly higher in the nonmotorized destinations than the motorized destinations. In terms of the socioeconomic variables, nonmotorists have higher income and education levels than motorists. Nonmotorists have a higher percentage of Hispanic population; motorists have a higher proportion of AfricanAmerican population. For the travel time, nonmotorists spent less time (TRIP_T) than motorists. This is an expected result because nonmotorized modes are typically for a short-distance commute due to a physical limit as to how much an individual can travel by foot or bicycle.

\section{Model results}

Table 3 presents the results estimated from the two models: MNL and NLM. While both models are theoretically sound, the NLM approach performs better than the MNL approach in terms of model fits. The -2 Log likelihood ratio decreased from 1291.8 (absolute value of -645.9 multiplied by 2) to 1164.4 (absolute value of -582.2 multiplied by 2), resulting in an improved Akaike Information Criterion (AIC) score. Consequently, (pseudo) R-squared values in NLM increased more than twice that of the MNL. The NLM approach is significantly different from the MNL because the Chi-squared value with two degrees of freedom at $1 \%$ level is 9.210 , which is substantially smaller than the difference in the Chi-squared values between the models (i.e., $189.9=352.8-162.9)$.

Table 3. Results of Multinomial logit model (MNL) vs. Nested logit model (NLM)

\begin{tabular}{|c|c|c|c|c|c|c|c|c|c|c|}
\hline \multirow{3}{*}{ Categories } & \multirow{3}{*}{ Variables } & \multicolumn{4}{|c|}{ MNL } & \multicolumn{4}{|c|}{ NLM } & \multirow{3}{*}{$\begin{array}{l}\text { VIF } \\
\text { Test }\end{array}$} \\
\hline & & \multicolumn{2}{|c|}{ NCD_Auto ${ }^{1}$} & \multicolumn{2}{|c|}{ CD_Auto ${ }^{2}$} & \multicolumn{2}{|c|}{ NCD_Auto } & \multicolumn{2}{|c|}{ CD_Auto } & \\
\hline & & Coef. & S.E. & Coef. & S.E. & Coef. & S.E. & Coef. & S.E. & \\
\hline \multicolumn{11}{|c|}{ Destination Choice Model } \\
\hline & Constant & $-2.4888 * * *$ & 0.3333 & & & -1.7494 & $0.84 \times 10^{7}$ & & & \\
\hline \multirow{2}{*}{ Design } & ST_DEN & $0.1851 *$ & 0.1016 & & & 0.0338 & 0.1276 & & & 1.32 \\
\hline & W_INX & $0.0307 * *$ & 0.0122 & & & $0.0572 * * *$ & 0.0173 & & & 4.28 \\
\hline \multirow{3}{*}{ Destination } & FOOD & 0.0071 & 0.0066 & & & $0.0205 * *$ & 0.0093 & & & 2.76 \\
\hline & TSTOPS & $0.0097 * *$ & 0.0039 & & & $0.0154 * * *$ & 0.0055 & & & 2.72 \\
\hline & SCHLS & 0.2594 & 0.1644 & & & $0.3227 *$ & 0.1805 & & & 1.15 \\
\hline Travel time & TRIP_T & 0.0008 & 0.0030 & & & $0.0081 *$ & 0.0041 & & & 0.93 \\
\hline \multicolumn{11}{|c|}{ Mode Choice Model } \\
\hline & Constant & $3.9859 * * *$ & 1.1328 & 0.0781 & 1.1729 & 3.2466 & $0.84 \times 10^{7}$ & $-1.2272 *$ & 0.7247 & \\
\hline Density & ACT_DEN & $-0.0207 * * *$ & 0.0049 & -0.0021 & 0.0044 & $0.0547 * *$ & 0.0261 & $-0.0063 *$ & 0.0033 & 1.72 \\
\hline \multirow{3}{*}{ Diversity } & LU_MIX & $1.2711 *$ & 0.7409 & -0.0031 & 0.7682 & $11.1439 * *$ & 4.4469 & $-1.1805 * * *$ & 0.4334 & 1.88 \\
\hline & LU_DIS & 0.0493 & 0.0560 & $0.0982 *$ & 0.0548 & $-1.9672 * * *$ & 0.6529 & $0.2536 * * *$ & 0.0523 & 1.07 \\
\hline & LU_ENT & -1.2001 & 1.2607 & -0.9283 & 1.3601 & 9.2641 & 6.4932 & $-1.3202 *$ & 0.7500 & 1.43 \\
\hline
\end{tabular}




\begin{tabular}{|c|c|c|c|c|c|c|c|c|c|c|}
\hline & H_MIX & $-0.7850 * *$ & 0.3465 & 0.1029 & 0.3654 & 1.0089 & 1.5620 & -0.1863 & 0.1912 & 1.39 \\
\hline \multirow{2}{*}{ Design } & $4 \mathrm{~W} \_\mathrm{INT}$ & $-0.0258 * * *$ & 0.0080 & 0.0030 & 0.0083 & 0.0590 & 0.0424 & -0.0066 & 0.0047 & 1.09 \\
\hline & BIKE & 0.0925 & 0.0578 & 0.0991 & 0.0609 & $1.4094 * * *$ & 0.4071 & $-0.1646 * * *$ & 0.0429 & 1.09 \\
\hline Travel time & TRIP_T & 0.0059 & 0.0045 & 0.0008 & 0.0030 & $-0.0555 *$ & 0.0323 & $0.0081 *$ & 0.0041 & 1.05 \\
\hline \multirow{8}{*}{$\begin{array}{l}\text { Socio- } \\
\text { demographic }\end{array}$} & LOW_INC & $-0.6705 *$ & 0.3716 & -0.5781 & 0.3839 & 1.8698 & 1.6738 & -0.2591 & 0.2162 & 1.45 \\
\hline & MED_INC & $-1.2214 * * *$ & 0.2882 & $-1.0610 * * *$ & 0.3002 & $2.7922 *$ & 1.4312 & $-0.3884 * *$ & 0.1648 & 1.28 \\
\hline & HH_SIZE & -0.1353 & 0.0861 & -0.0877 & 0.0884 & 0.2878 & 0.3699 & -0.0461 & 0.0467 & 1.10 \\
\hline & EDUC31 & $-0.7066 * * *$ & 0.2640 & $-0.5226 *$ & 0.2738 & -1.5877 & 1.1967 & 0.1439 & 0.1453 & 1.18 \\
\hline & HIS_R & -0.4588 & 0.4138 & -0.3074 & 0.4285 & 0.9211 & 1.8995 & -0.2206 & 0.2392 & 1.23 \\
\hline & AS_R & 0.1439 & 0.5132 & 0.4749 & 0.5306 & -6.4920 & 4.5227 & 0.7179 & 0.4620 & 1.07 \\
\hline & AA_R & $1.1803 * *$ & 0.5698 & $1.2716^{* *}$ & 0.5642 & -1.8033 & 1.9322 & 0.2680 & 0.2336 & 1.06 \\
\hline & GENDER & -0.0728 & 0.2370 & 0.1872 & 0.2472 & $-2.7341 * *$ & 1.1865 & $0.3137 * *$ & 0.1547 & 0.92 \\
\hline \multirow{2}{*}{ IV } & \multicolumn{4}{|l|}{ Clustered } & & $-11.2038 * *$ & \multicolumn{4}{|l|}{4.8033} \\
\hline & \multicolumn{5}{|c|}{ Non-Clustered } & 1.0000 & \multicolumn{4}{|l|}{ Fixed } \\
\hline \multicolumn{2}{|c|}{ Log Likelihood for Choice } & \multicolumn{4}{|l|}{-645.9180} & \multicolumn{5}{|l|}{-582.1863} \\
\hline \multicolumn{2}{|c|}{ AIC } & \multicolumn{4}{|l|}{2.9471} & \multicolumn{5}{|l|}{1.6534} \\
\hline \multicolumn{2}{|l|}{ R_sq } & \multicolumn{4}{|l|}{0.1120} & \multicolumn{5}{|l|}{0.2332} \\
\hline \multicolumn{2}{|l|}{ Adj_R_sq } & \multicolumn{4}{|l|}{0.0871} & \multicolumn{5}{|l|}{0.2117} \\
\hline \multicolumn{2}{|l|}{ Chi_Sq } & \multicolumn{4}{|l|}{$162.8948 * * *$} & \multicolumn{5}{|l|}{$352.7690 * * *$} \\
\hline \multicolumn{2}{|l|}{$\mathrm{N}$} & \multicolumn{4}{|l|}{751} & \multicolumn{5}{|l|}{751} \\
\hline
\end{tabular}

Note 1. NCD_Auto $=$ motorized destinations in the non-clustered group

2. CD_Auto $=$ motorized destinations in the clustered group,

3. Reference group is CD_Nonmotorized (nonmotorized destinations in the clustered group)

4. LU_DIS was multiplied by 100, and BIKE was divided by 1000 to adjust decimal points of the estimated coefficients.

5. $*<0.10, * *<0.05, * * *<0.01$

Destination choice model

The NLM results suggest that the types of land use surrounding trip destinations affect traveler's destination choice. The results clearly show that popular trip destinations, such as schools (SCHLS), food and restaurant establishments (FOOD), and transit stops (TSTOPS), attract significantly more trips. This result confirms our hypothesis that certain destination characteristics attract people more to the destinations, irrespective of their modal behaviors. In addition, walkability index (W_INX) shows a strong positive correlation with the nonmotorized destinations. The high walkability index implies flexible route choice and the high levels of network connectivity for nonmotorized travelers. The result suggests that destinations with better access and flexible route choice can attract more nonmotorized travels. Interestingly, the NLM result indicates that total travel time (TRIP_T) is positively associated with the destination choice. Although the estimated coefficient for travel time is only marginally significant, this result suggests that travel time is likely to be an important factor for destination choice.

Interestingly, the NLM result indicates that total travel time (TRIP_T) is positively associated with the destination choice. While the significance level of the estimated coefficient is not so strong, this result resonates with the common wisdom that nonmotorized transportation is suitable for shorter travel than a longer one. Previous studies also confirm that travel time is one 
of the most important factors in mode choice decision (Frank, Bradley, et al. 2007). This result implies that nonmotorized transportation can be a feasible alternative to an automobile when trip destinations are within a short distance.

\section{$\underline{\text { Mode choice model }}$}

The NLM approach appears to be more accurate than the MNL approach in terms of describing the relationship between the built environment and mode choice behavior. In the MNL model, few built environment variables were statistically significant. However, the NLM results suggest that the built environment characteristics at trip destinations are significantly associated with mode choice. Most of the built environment variables, which reflect the degrees of density, diversity, and design, are statistically significant in the NLM model. ${ }^{1}$ In terms of the density measure, net population and employment density (ACT_DEN) is positively associated with nonmotorized mode choice. For the diversity measures, the mix of land uses (LU_MIX) supports nonmotorized mode over motorized mode. Land use diversity index (LU_DIS) is also positively associated with motorized mode choice; whereas nonmotorized mode choice is more positively associated with land use mix (LU_MIX) and land use entropy (LU_ENT). For the design element, the length of bicycle facilities (BIKE) is positively associated with nonmotorized mode choice in the clustered group; whereas the estimated coefficient for the same variable in the non-clustered group is in the opposite direction. On net, land use diversity at trip destinations attracts motorists, and yet balanced land uses, especially between residential and non-residential uses, attract nonmotorists at trip ends. These results suggest that the impact of destination characteristics on mode choice varies by different modal behavior.

In terms of the demographic and socioeconomic factors, three out of eight sociodemographic variables are significantly associated with mode choice decisions in the MNL model, but some of the signs of the parameter estimates are in the unexpected direction. Compared to the MNL model, the NLM model provides less support for linking socioeconomic factors with mode choice. Only household income is significantly associated with nonmotorized mode choice. Both NLM and MNL approaches consistently estimate negative coefficients for income, suggesting that people in median income level prefer nonmotorized travel more than those in high-income level in the clustered group. These results suggest that, while higher income groups may prefer automobile more than low- and median-income groups in the clustered destinations, the median-income group is more likely to walk or bicycle to the clustered destinations and drive a car to the non-clustered destinations.

\section{Discussion}

This study presents a systemic approach to determine the impact of the built environment at trip destinations on travel behavior. Analogous to previous studies on residential built environment (Cao et al. 2007; Frank et al. 2007; Kitamura et al. 1997; Levine and Frank 2007),

\footnotetext{
${ }^{1}$ Negative and statistically significant parameter estimates in the CD Auto column (nonmotorized mode choice in the clustered group) indicates positive and significant estimates for nonmotorized mode choice in the clustered group.
} 
the present study provides evidence that the built environment at trip destinations can also significantly influences travel decisions. The NLM destination choice model suggests that nonmotorized trips are clustered in areas with schools, retail shops and restaurants, and transit stops as well as pedestrian-friendly areas within the City of Long Beach. In particular, the influence of walkability index variable (W_INX) indicates the importance of connectivity for pedestrians around trip destinations. The latest planning efforts such as Complete Streets and Transit-Oriented Development (TOD) aim to improve the walkability around transit stations, main streets, and urban boulevard (Dock et al. 2012). These targeted areas tend to closely locate around trip destinations rather than trip origins which are typically residential neighborhoods. Therefore, our results adequately support the overall direction of the current planning efforts focused on travel routes and destinations.

The results also suggest that the built environment features in the clustered group significantly influence individual's mode choice decision. Such destination characteristics include population and employment density, land use mix, land use entropy, and length of bicycle facilities. Interestingly, our models consistently found significant relationship between the density measure and nonmotorized mode choice. This result is quite different from previous studies where little or no effect of residential density has been observed for non-work travel (Greenwald and Boarnet 2001; Crane and Crepeau 1998). Rodriguez and Joo (2004) have found similar results with nonmotorized travel for utilitarian purpose, which led them to conclude that employment densities at destinations appear to have stronger influence on mode choice than residential densities at origins. Consistent with previous studies (Krizek 2006; Moudon et al. 1997), we also found a close link between presence of nonmotorized facilities and mode choice. These findings imply that the presence of diverse amenities at destinations and facilities targeted to a specific mode may be more important factors for nonmotorists than motorists.

Another interesting finding from this study is that the land use dissimilarity index (LU_DIS) positively affects motorized mode choice while land use mix (LU_MIX) and balance (LU_ENT) more positively affect nonmotorized mode. It seems counterintuitive that dissimilar land use attracts more motorized trips. However, higher dissimilarity measure also means that the destination is an interesting place to visit. This is consistent with previous studies where diversity index has been positively related with automobile trips (Ewing et al. 2015). The same logic may not apply to nonmotorists because there is a certain limit as to how far pedestrians and bicyclists can travel. Because a trip usually starts from a residential area and ends at a nonresidential area, good land use mix and balance possibly means shorter distance between trip beginning and end. Since walking and bicycling are more suitable within a short distance, it is plausible to argue that good land use mix and balance may attract nonmotorized mode choice, but diversity index may not be as important as other diversity measures for nonmotorized travel.

This finding also suggests the importance of service scale offered by diverse land uses. Since the variable, LU_DIS, simply counts the numbers of different land use types, the destinations with higher dissimilarity measure can include the destinations offering a variety of services in small scale at separated locations. On the other hand, LU_MIX and LU_ENT 
measure the number of diverse land use types as well as the proportional composition of their areas. Thus, the destinations with high LU_MIX and LU_ENT scores mean the areas that provide diverse services in critical scale. For nonmotorized travel, therefore, more targeted strategies on the development of popular destinations in significant scale may work better and more effectively than applying services in smaller scale at dispersed locations.

Furthermore, this subtle difference between different travel modes suggests that route- and destination-based land use strategies may be more relevant in the context of pedestrian and bicycle planning. Our findings suggest that more important factor for nonmotorized travel is a travel time between origin and destination and an attractiveness factor at trip destination. In other words, the appropriate scale for nonmotorized destinations may not necessarily be large. This study suggests that popular destinations, such as a school or a restaurant, located within a reasonable travel distance (e.g. a quarter-mile) from residential areas can potentially attract more nonmotorized travel. In this sense, this study provides some evidence to support more targeted planning strategies, such as Safe Routes to School (SRTS), which focuses on the specific journey from home to school. It has been reported that this particular program has been generally successful in promoting walking and bicycle trips for school children (Boarnet et al. 2005; Stewart 2010).

\section{Conclusion}

This study attempts to shed light on the importance of the built environment factors of trip destination to which planners have conventionally less paid attention. By developing a nested logit model distinguishing the destination choice of nonmotorized mode from mode choice, this study confirms, this study clearly presents the unique built environment factors of trip destination that attract nonmotorized trips. Such destination characteristics as walkability, population and employment density, land use mix, land use entropy, and length of bicycle facilities make people to choose nonmotorized mode and attract the mode to particular destinations.

The findings from this study have important implications for transportation policy. Analogous to previous studies on residential land use, the built environment at trip destinations are also significantly associated with individual's destination and mode choice decisions. This finding raises an interesting question for planning practitioners and researchers - where should planners prioritize their strategies to promote nonmotorized travel with limited resources? If cities want to capture the full demand for nonmotorized travel, they should consider improving the built environments around popular destinations and connectivity to those destinations, not just residential neighborhoods. This study also provides some empirical support for constructing more targeted nonmotorized facilities which focuses on improving connections between trip origin and destination. Taken together, this study provides evidence to support built environment factors at both trip origin and destination for developing more effective nonomotorized transport policies. 
However, this study has limitations and implications addressed by future research. First, our sample size is relatively small due to lower rates of nonmotorized trips reported in the travel survey. It is impossible to make a generalization from the 751 trip destinations reported for one day in the sample. Thus, it would be necessary to replicate this study with larger samples and sufficient number of trip destinations to increase the validity of our findings. Second, the present study does not explicitly control for residential self-selection bias. Some people may have selected their residence due to their preference for certain travel modes. However, recent population growth of the city has been subpar (0.5\%) according to the 2010 census. Therefore, the effect of new movers on our findings could be marginal at best. We caution that some of our findings may be related to unobserved heterogeneity caused by individual preference for certain lifestyle. More explicit control for the self-selection effect, such as inclusion of attitudinal variables or propensity-score matching technique, would be desirable in future studies. Furthermore, this paper did not separate the nonmotorized trips to/from public transit stations and stops from other trips mainly due to the small number of nonmotorized trips. Since the characteristics of access/egress trips to/from public transit may differ from more common nonmotorized trips, further research needs to pay attention to different characteristics by trip purpose. Lastly, we combined walking and bicycle trips together to understand a general behavioral patterns of nonmotorized travelers. However, it would be ideal to split bicycle and pedestrian trips in future studies because the characteristics of pedestrians and bicyclists may be different from one another.

\section{References}

Alta Transportation Consulting. 2001. Long Beach Bicycle Master Plan. City of Long Beach, CA.

Axhausen, KW, and Tommy Gärling. 1992. "Activity-Based Approaches to Travel Analysis: Conceptual Frameworks, Models, and Research Problems." Transport Reviews 12 (4): 32341.

Badoe, DA, and EJ Miller. 2000. "Transportation-land-Use Interaction: Empirical Findings in North America, and Their Implications for Modeling." Transportation Research Part D: Transport and Environment 5 (4): 235-63.

Bartholomew, Keith, and Reid Ewing. 2008. "Land Use-Transportation Scenarios and Future Vehicle Travel and Land Consumption: A Meta-Analysis." Journal of the American Planning Association 75 (1): 13-27.

Ben-Akiva, Moshe E., and Michel Bierlaire. 1999. "Discrete Choice Methods and Their Applications to Short Term Travel Decisions." In Handbook of Transportation Science, edited by Randolph W. Hall, 5-34. New York: Springer Science+Business Media.

Bento, Antonio M, Maureen L Cropper, Ahmed M Mobarak, and Katja Vinha. 2005. "The Effects of Urban Spatial Structure on Travel Demand in the United States." Review of Economics and Statistics 87 (3). MIT Press: 466-78. 
Bhat, C, and J Guo. 2007. "A Comprehensive Analysis of Built Environment Characteristics on Household Residential Choice and Auto Ownership Levels." Transportation Research Part B: Methodological 41 (5): 506-26.

Boarnet, Marlon G., and Randall Crane. 2001. "The Influence of Land Use on Travel Behavior." Transportation Research Part A: Policy and Practice 35 (9).

Boarnet, Marlon G., Kristen Day, Craig Anderson, Tracy E Mcmillan, and Mariela Alfonzo. 2005. "California's Safe Routes to School Program: Impacts on Walking, Bicycling, and Pedestrian Safety." Journal of the American Planning Association 71 (3): 301-17. doi:10.1080/01944360508976700.

Boarnet, Marlon G., M. Greenwald, and Tracy E Mcmillan. 2008. "Walking, Urban Design, and Health: Toward a Cost-Benefit Analysis Framework." Journal of Planning Education and Research 27 (3): 341-58.

Boarnet, Marlon G., and Michael J Greenwald. 2000. "Land Use, Urban Design, and Nonwork Travel." Transportation Research Record: Journal of the Transportation Research Board 1722: 27-37.

Bowman, JL, and Moshe E. Ben-Akiva. 2000. "Activity-Based Disaggregate Travel Demand Model System with Activity Schedules.” Transportation Research Part A: Policy and Practice 35: 1-28.

Boyce, David. 2002. "Is the Sequential Travel Forecasting Paradigm Counterproductive?" Journal of Urban Planning and Development 128 (4): 169-83.

Brownstone, D, and T Golob. 2009. The Impact of Residential Density on Vehicle Usage and Energy Consumption. Journal of Urban Economics. Vol. 65.

Bussel, Jamie B, Laura C Leviton, and C Tracy Orleans. 2009. "Active Living by Design: Perspectives from the Robert Wood Johnson Foundation." American Journal of Preventive Medicine 37 (6 Suppl 2). Elsevier Inc.: S309-12. doi:10.1016/j.amepre.2009.09.019.

Calthorpe, P. 1993. The next American Metropolis: Ecology, Community, and the American Dream. New York: Princeton Architectural Press.

Cao, Xinyu (Jason), Patricia L. Mokhtarian, and Susan L. Handy. 2007. "Do Changes in Neighborhood Characteristics Lead to Changes in Travel Behavior? A Structural Equations Modeling Approach." Transportation 34 (5): 535-56.

. 2009. "Examining the Impacts of Residential Self-Selection on Travel Behaviour: A Focus on Empirical Findings." Transport Reviews 29 (3): 359-95.

Cervero, Robert, and Michael Duncan. 2003. "Walking, Bicycling, and Urban Landscapes: Evidence from the San Francisco Bay Area." American Journal of Public Health 93 (9): 1478-83.

Cervero, Robert, and Kara Kockelman. 1997. "Traffic Demand and the 3Ds: Density, Diversity, and Design." Transportation Research Part D: Transport and Environment 2 (3): 199-219.

Cervero, Robert, Olga L. Sarmiento, Enrique Jacoby, Luis Fernando Gomez, and Andrea Neiman. 2009. "Influences of Built Environments on Walking and Cycling: Lessons from Bogotá." International Journal of Sustainable Transportation 3 (4): 203-26.

Chatman, Daniel G. 2009. "Residential Choice, the Built Environment, and Nonwork Travel: Evidence Using New Data and Methods." Environment and Planning A 41 (5): 1072-89.

City of Long Beach. "Bike Long Beach: Your Resource for Local Bicycling News and Updates." http://www.bikelongbeach.org/. 
Crane, Randall, and Richard Crepeau. 1998. "Does Neighborhood Design Influence Travel?: A Behavioral Analysis of Travel Diary and GIS Data.” Transportation Research Part D: Transport and Environment 3 (4): 225-38.

De Nazelle, Audrey, Mark J Nieuwenhuijsen, Josep M Antó, Michael Brauer, David Briggs, Charlotte Braun-Fahrlander, Nick Cavill, et al. 2011. Improving Health through Policies That Promote Active Travel: A Review of Evidence to Support Integrated Health Impact Assessment. Environment International. Vol. 37.

Dock, Frederick C., Ellen Greenberg, and Mark Yamarone. 2012. "Multimodal and Complete Streets Performance Measures in Pasadena, California." ITE Journal (Institute of Transportation Engineers) 82 (1): 33-37.

Domencich, Thomas, and Daniel McFadden. 1975. Urban Travel Demand. Amsterdam: NorthHolland.

Duany, Andres, Elizabeth Plater-Zyberk, and Jeff Speck. 2001. Suburban Nation: The Rise of Sprawl and the Decline of the American Dream. New York, NY: Farrar, Straus and Giroux.

Ewing, Reid, and Robert Cervero. 2010. "Travel and the Built Environment." Journal of the American Planning Association 76 (3): 265-94.

Ewing, Reid, J Goates P, Michael Greenwald, Ming Zhang, Arthur Nelson C, and William Greene H. 2014. "Varying Influences of the Built Environment on Household Travel in 15 Diverse Regions of the United States." Urban Studies, 1-9. doi:10.1177/0042098014560991.

Ewing, Reid, G. Tian, J. Goates, M. Zhang, M. J. Greenwald, A. Joyce, J. Kircher, and W. Greene. 2015. "Varying Influences of the Built Environment on Household Travel in 15 Diverse Regions of the United States." Urban Studies, December. doi:10.1177/0042098014560991.

Forsyth, Ann, and Kevin Krizek. 2011. "Urban Design: Is There a Distinctive View from the Bicycle?" Journal of Urban Design 16 (4): 531-49.

Frank, Lawrence D., and Gary Pivo. 1994. "Impacts of Mixed Use and Density on Utilization of Three Modes of Travel: Single-Occupant Vehicle, Transit, and Walking." Transportation Research Record 1446: 44-52.

Frank, Lawrence D., Brian E Saelens, Ken E Powell, and James E Chapman. 2007. “Stepping towards Causation: Do Built Environments or Neighborhood and Travel Preferences Explain Physical Activity, Driving, and Obesity?" Social Science \& Medicine (1982) 65 (9): 1898-1914.

Giles-Corti, Billie, and Robert J Donovan. 2002. "The Relative Influence of Individual, Social and Physical Environment Determinants of Physical Activity." Social Science \& Medicine 54 (12): 1793-1812.

Greene, William H. 2011. Econometric Analysis. 7th ed. Essex, UK: Pearson.

Greenwald, Michael J, and Marlon G. Boarnet. 2001. "Built Environment as Determinant of Walking Behavior: Analyzing Nonwork Pedestrian Travel in Portland, Oregon." Transportation Research Record: Journal of the Transportation Research Board 1780: 3342.

Handy, Susan L. 1993. "Regional Versus Local Accessibility : Implications for Nonwork Travel." Transportation Research Record: Journal of the Transportation Research Board, no. 234: 58-66. 
. 2002. "Travel Behaviour - Land Use Interactions: An Overview and Assessment of the

Research.” In In Perpetual Motion: Travel Behavior Research Opportunities and

Application Challenges, edited by H. S. Mahmassani. Oxford, UK: Elsevier Science.

Handy, Susan L., Marlon G. Boarnet, Reid Ewing, and Richard E Killingsworth. 2002. "How the Built Environment Affects Physical Activity: Views from Urban Planning." American Journal of Preventive Medicine 23 (2 Suppl): 64-73.

Handy, Susan L., Xinyu (Jason) Cao, and P.L. Mokhtarian. 2006. "Self-Selection in the Relationship between the Built Environment and Walking: Empirical Evidence from Northern California." Journal of the American Planning Association 72 (1). Routledge: 5574.

Iacono, Michael, K Krizek, and AM El-Geneidy. 2008. Access to Destinations: How Close Is Close Enough? Estimating Accurate Distance Decay Functions for Multiple Modes and Different Purposes. St. Paul, MN.

Iacono, Michael, Kevin J. Krizek, and Ahmed El-Geneidy. 2010. "Measuring Non-Motorized Accessibility: Issues, Alternatives, and Execution." Journal of Transport Geography 18 (1): 133-40.

Joh, K., M. T. Nguyen, and M. G. Boarnet. 2011. "Can Built and Social Environmental Factors Encourage Walking among Individuals with Negative Walking Attitudes?” Journal of Planning Education and Research 32 (2): 219-36. doi:10.1177/0739456X11427914.

Kitamura, Ryuichi, PL Mokhtarian, and Laura Laidet. 1997. "A Micro-Analysis of Land Use and Travel in Five Neighborhoods in the San Francisco Bay Area." Transportation 24: 125-58.

Knaap, Gerrit, and Emily Talen. 2005. "New Urbanism and Smart Growth: A Few Words from the Academy." International Regional Science Review 28 (2): 107-18.

Krizek, KJ. 2006. "Proximity to Trails and Retail: Effects on Urban Cycling and Walking." Journal of American Planning Association 72 (1): 33-42.

Kuzmyak, J Richard, Jerry Walters, Hsi-hwa Hu, Jason Espie, and Dohyung Kim. 2012. Travel Behavior and Built Environment: Exploring the Importance of Urban Design at the NonResidential End of the Trip. Lincoln Institute of Land Policy Working Paper WP12RK1.

Levine, Jonathan, and Lawrence D. Frank. 2007. "Neighborhood Choices : The Sufficiency of Compact Development in the Atlanta Region." Transportation, 255-74.

Liao, Tim Futing. 1994. Interpreting Probability Models: Logit, Probit and Other. Generalized Linear Models. Thousand Oaks, CA: Sage.

Liu, Feng, John E. (Jay) Evans, and Thomas Rossi. 2012. "Recent Practices in Regional Modeling of Nonmotorized Travel." Transportation Research Record: Journal of the Transportation Research Board 2303: 1-8. doi:10.3141/2303-01.

Mitchell, Andy. 2005. The ESRI Guide to GIS Analysis, Volume 2: Spatial Measurements and Statistics. Redlands, CA: Environmental Systems Research Institute (ESRI).

Mokhtarian, Patricia L. 2008. "Examining the Impacts of Residential Self-Selection on Travel Behavior: A Focus on Methodologies." Transportation Research 42 (3): 204-28.

Moudon, Av, P Hess, Mc Snyder, and K Stanilov. 1997. "Effects of Site Design on Pedestrian Travel in Mixed Use, Medium-Density Environments." Transportation Research Record, no. 1578. doi:10.3141/1578-07.

National Academy of Sciences. 2009. Driving and the Built Environment: The Effects of Compact Development on Motorized Travel, Energy Use, and CO2 Emissions -- Special Report 298. Washington, DC: The National Academies Press. 
Newman, Jeffrey P., and Vincent L. Bernardin. 2010. "Hierarchical Ordering of Nests in a Joint Mode and Destination Choice Model." Transportation 37 (4): 677-88.

Ortuzar, Juan de Dios, and Luis G. Willumsen. 2011. Modelling Transport. 4th ed. Wiley.

Pinjari, Abdul Rawoof, Ram M. Pendyala, Chandra R. Bhat, and Paul a. Waddell. 2007.

"Modeling Residential Sorting Effects to Understand the Impact of the Built Environment on Commute Mode Choice." Transportation 34 (5): 557-73.

. 2011. "Modeling the Choice Continuum: An Integrated Model of Residential Location, Auto Ownership, Bicycle Ownership, and Commute Tour Mode Choice Decisions." Transportation 38 (6): 933-58.

Plaut, P. 2005. "Non-Motorized Commuting in the US." Transportation Research Part D: Transport and Environment 10 (5): 347-56. doi:10.1016/j.trd.2005.04.002.

Pucher, John, and Ralph Buehler. 2010. "Walking and Cycling for Healthy Cities." Built Environment 36 (4). Alexandrine Press: 391-414.

Rodríguez, Daniel a., and Joonwon Joo. 2004. "The Relationship between Non-Motorized Mode Choice and the Local Physical Environment." Transportation Research Part D: Transport and Environment 9 (2): 151-73. doi:10.1016/j.trd.2003.11.001.

Saelens, Brian E, James F. Sallis, and Lawrence D. Frank. 2003. "Environmental Correlates of Walking and Cycling: Findings from the Transportation, Urban Design, and Planning Literatures." Annals of Behavioral Medicine: A Publication of the Society of Behavioral Medicine 25 (2): 80-91.

Sallis, James F. 2009. Measuring Physical Activity Environments: A Brief History. American Journal of Preventive Medicine. Vol. 36.

Sallis, James F., Robert B Cervero, William Ascher, Karla a K.A. Henderson, M.K. Katherine Kraft, and Jacqueline Kerr. 2006. "An Ecological Approach to Creating Active Living Communities." Annual Review of Public Health 27 (1): 297-322. doi:10.1146/annurev.publhealth.27.021405.102100.

Shafizadeh, K., and D. Niemeier. 1997. Bicycle Journey-to-Work: Travel Behavior Characteristics and Spatial Attributes. Transportation Research Record: Journal of the Transportation Research Board. Vol. 1578.

Siegel, Justin D., Joaquín Cea, José Enrique Fernández, Renán E. Rodriguez, and David Boyce. 2006. "Comparisons of Urban Travel Forecasts Prepared with the Sequential Procedure and a Combined Model." Networks and Spatial Economics 6 (2): 135-48.

Small, Kenneth A., and Erik T. Verhoef. 2007. "Travel Demand." In The Economics of Urban Transportation, 2nd ed., 4-5. London and New York: Routledge.

Stewart, O. 2010. "Findings from Research on Active Transportation to School and Implications for Safe Routes to School Programs." Journal of Planning Literature 26 (2): 127-50. doi:10.1177/0885412210385911.

Van Acker, Veronique, Bert Van Wee, and Frank Witlox. 2010. "When Transport Geography Meets Social Psychology: Toward a Conceptual Model of Travel Behaviour.” Transport Reviews 30 (2): 219-40.

Woodcock, James, David Banister, Phil Edwards, Andrew M Prentice, and Ian Roberts. 2007. "Energy and Transport." Lancet 370 (9592): 1078-88.

Zhang, Ming. 2004. "The Role of Land Use in Travel Mode Choice: Evidence from Boston and Hong Kong.” Journal of the American Planning Association 70 (3): 344-60. 